\title{
Somatotypes of athletes with physical disabilities and the type of activity they undertake
}

Authors' Contribution: A Study Design

B Data Collection

C Statistical Analysis

D Data Interpretation

E Manuscript Preparation

F Literature Search

G Funds Collection

\author{
Agata Kamionka1 ABCDEFG, Elżbieta Grzywacz ${ }^{2}$, Mariusz Lipowski ${ }^{1}$ CDG \\ ${ }^{1}$ Faculty of Physical Culture, \\ Gdansk University of Physical Education and Sport, Gdansk, Poland \\ ${ }^{2}$ Pomeranian Medical University in Szczecin, Szczecin, Poland
}

\section{abstract}

Background: The issue of scientific measurement of somatotypes of athletes with physical disabilities and the type of physical activity undertaken by them is poorly documented in the literature. The aim of the study is to determine what type of body composition is characteristic of athletes with physical disabilities, engaging in various types of physical activity, such as swimming, sitting volleyball and weight lifting.

Material and methods:

Sixty men, aged 20-30, were qualified for the study. Each study participant had a motor dysfunction and was in intellectual norm. For the research protocol, Sheldon's typology in Heath and Carter modification was used.

Results: The group of men with physical disabilities practicing swimming regularly had the advantage of endomorphic and mesomorphic components. A similar distribution of components in the somatotype was demonstrated by men playing sitting volleyball. Men lifting weights clearly showed the dominance of the mesomorphic component and, to a small extent, the share of the ectomorphic and endomorphic components.

Conclusions: A properly calculated somatotype allows disabled athletes to learn about body composition components and to train and develop more effectively in a particular physical activity.

Key words: somatotype, Sheldon typology, Heath-Carter, disabled athletes, body typese.

\section{article details}

Article statistics: Word count: 4,110; Tables: 5; Figures: 6; References: 28

Received: July 2020; Accepted: August 2020; Published: September 2020

Full-text PDF: http://www.balticsportscience.com

Copyright @ Gdansk University of Physical Education and Sport, Poland

Indexation: Celdes, Clarivate Analytics Emerging Sources Citation Index (ESCI), CNKI Scholar (China National Knowledge Infrastructure), CNPIEC, De Gruyter - IBR (International Bibliography of Reviews of Scholarly Literature in the Humanities and Social Sciences), De Gruyter - IBZ (International Bibliography of Periodical Literature in the Humanities and Social Sciences), DOAJ, EBSCO - Central \& Eastern European Academic Source, EBSCO - SPORTDiscus, EBSCO Discovery Service, Google Scholar, Index Copernicus, J-Gate, Naviga (Softweco, Primo Central (ExLibris), ProQuest - Family Health, ProQuest - Health \& Medical Complete, ProQuest - Illustrata: Health Sciences, ProQuest - Nursing \& Allied Health Source, Summon (Serials Solutions/ProQuest, TDOne (TDNet), Ulrich's Periodicals Directory/ulrichsweb, WorldCat (OCLC)

Funding: This research received no specific grant from any funding agency in the public, commercial, or not-for-profit sectors. Authors have declared that no competing interest exists.

Corresponding author: Agata Kamionka, Gdansk University of Physical Education and Sport; ul. Kazimierza Górskiego 1, 80-336 Gdansk, Poland; e-mail: agata.kamionka@awf.gda.pl

Open Access License: This is an open access article distributed under the terms of the Creative Commons Attribution-Non-Commercial-NoDerivatives 4.0 International (https://creativecommons.org/licenses/by-nc-nd/4.0/), which permits use, distribution, and reproduction in any medium, provided the original work is properly cited, the use is non-commercial and is otherwise in compliance with the license. 


\section{INTRODUCTION}

The issue of scientific measurement of the somatotypes of athletes with physical disabilities and the type of physical activity undertaken by them is poorly documented in the literature. The authors of this study had difficulties in referring to any research that could show how physically disabled athletes' body shape affects the type of physical activity they practice. The majority of the studies presented in the literature refer to the study of somatotypes of able-bodied athletes of various sports, such as: triathlon [1], artistic gymnastics [2], athletics [3], canoeing, football, basketball [4], or volleyball [5, 6, 7].

For people with disabilities sport is significant in complementing the rehabilitation process and building social relations among people with mobility disabilities. More and more attention is paid to the elicitation of people with physical disabilities in amateur sports and professional activities. However, it is noted that the elicitation of disabled people in sport is smaller and requires more support [8, 9].

Physical morphology or physique is important for optimizing sport results in many different sports disciplines [10]. The physique of an athlete with physical disability is the foundation of his sporting success. It is significantly associated with predispositions in individualized types of physical activity. In the subject literature, it is noted that the issue of sport for people with disabilities remains a niche topic.

Among the most popular methods of assessing somatotypes of able-bodied athletes is Sheldon's typology in Heath-Carter modification. It is widely used in sport and health science $[3,11,12,13]$. The vast majority are studies on the somatotype of physically disabled people who undertake regular sport activity $[14,15]$.

The type of physical exertion among people undertaking physical activity is a very important aspect and significantly associated with achieving success in motor skills in a particular physical activity. The used type of physical effort is significant for people with full motor skills and is the key in the motor training process of people with physical disabilities. Many forms of physical activity have a mixed type of effort (swimming, basketball, volleyball, dance) [16]; however, there are those where static and strength effort prevails, for example during lifting weights [16-19]. The effort applied during physical activity affects the quality of endurance, cardio-respiratory capacity and strength [20]. The training type significantly affects the body composition of an athlete with a disability [21].

The aim of the study is to determine what type of body structure is characteristic of an athlete with physical disability, engaging in various types of physical activity such as swimming, sitting volleyball and weight lifting. The types of physical activity chosen by the authors are intentional, due to the different specifics of the type of physical effort and are associated with various body predispositions of persons with physical disabilities. The selected activities represent mixed effort (swimming, volleyball) and static (weightlifting) types. It is also noted that the physical activities indicated by the authors are poorly described in the literature.

The authors of this study want to pay special attention to the above-mentioned topic due to the limited amount of scientific work on the correlation of the somatotype with the type of physical activity practiced by athletes with physical disabilities, such as swimming, sitting volleyball and weight lifting. 


\section{MATERIAL AND METHODS}

\section{ETHIC STATEMENT}

All research procedures were carried out in accordance with ethical standards of research involving people and the Helsinki Declaration of 1964 (as amended). Each participant expressed an oral consent to undergo tests and was informed about the possibility of withdrawing from the measurements.

\section{STATISTICAL METHODS}

The Spearman correlation was used to investigate the relationship between the somatotype components of swimmers, volleyball players and weightlifters. Additionally, to assess the relationship between individual components, the arithmetic mean, mode, median and standard deviation were used. The arithmetic mean and standard deviation were also used to analyze the subjects' age.

\section{PARTICIPANTS}

Sixty men, aged 20-30 ( $\overline{\mathrm{x}}=26, \mathrm{SD}=3.028)$, were qualified for the study. Each study participant had motor dysfunction and was in intellectual norm. The study group was qualified for anthropometric measurements using the applicable disability categories established by the International Paralympic Committee. A group of men after amputation, various musculoskeletal disorders and paraplegia qualified for the study. All sports and medical classes were allowed in each category. The group of examined men had the following body dysfunctions: lack of upper or lower limb, myelomeningocele, foot deformation, neurological deficits associated with hemiparesis or limb paresis of lower limbs. The studied group, in individual physical activities, had to regularly participate in motor training created by swimming, volleyball and weightlifting trainers. Participants who had mental disorders, exhibited intellectual disability and showed lack of regularity in motor training were excluded. Men were active participants of the provincial association of disabled people dealing with the activation of disabled people in sport activities. The non-governmental organization favors the development of physical culture of people with disabilities, prepares them for sports competitions and supports recreational motor activity.

\section{PROTOCOL}

The tests were carried out in a large city in 2015, during training of individual sports groups (swimming, sitting volleyball, weight lifting). For the research protocol, Sheldon's typology in Heath and Carter modification was used.

Before starting anthropometric measurements, an interview with each participant and the trainee was conducted. The interview was divided by the authors into individual categories regarding the following data: age, sex, sociodemographic and clinical data. During the interview, the inclusion and exclusion criteria from the study group were taken into account. The interview also contained information on the current health status and sports activities. In addition, the trainers confirmed the sport and medical class that the players have during competitions and sport friendly meetings. During the study of anthropometric measurements, the trainer of the given section accompanied the competitor. The measurement was taken when the participant was without outer clothing. Measurement without outerwear was required because of the 
accuracy of the measurements. After the interview, individual anthropometric measurements were taken to assess body composition components: endomorphy (measure of fatness), mesomorphy (measure of massiveness), ectomorphy (assessment of slenderness). The resulting body composition components gave an individualized code called a somatotype. Anthropometric measurements were performed in the same way for each participant of the study.

\section{MEASUREMENTS}

The endomorphic component was assessed on the basis of the sum of three skinfat folds: on the shoulder, under the shoulder blade and above the iliac plate. Anthropometric measurements were performed on both sides of the body with the PRZDNS-TMX-119 tissue meter. The skin-fat fold on the arm was measured while the participant was sitting in a chair without backrest, where the athlete's lower limbs were positioned in the flexion of the hip, knee and ankle joint of 90 degrees. Upper limbs were relaxed and hands were put on thighs. The measurement was made by placing the tissue meter vertically in the middle of the length of the triceps on both side of the arm. The measurement of skin-fat fold under the shoulder blade was also taken in the position indicated above. Measurement made with an oblique tissue meter, $2 \mathrm{~cm}$ at the lower angle of the shoulder blade and $2 \mathrm{~cm}$ in the medial direction. The exact distance was assessed using anthropometric tape and then the place of measurement was marked with a marker. The measurement was taken on the right and left side of the tested person's body. The last skin-fat fold above the iliac plate was also measured in a sitting position while maintaining the same methodology, by measuring vertically in the lateral line of the body above the iliac plate on the right and left side of the body. Then the obtained measurements were added together and the obtained value was referred to the endomorphic point value read from the table (Table 1 ).

Table 1. The first somatotype component - endomorphy [22]

\begin{tabular}{cc} 
Sum of skin - fat folds & Point value \\
\hline $7.0-10.9$ & $1 / 2$ \\
$11.0-14.9$ & 1 \\
$15.0-18.9$ & $1 / 2$ \\
$19.0-22.9$ & $21 / 2$ \\
$23.0-26.9$ & 3 \\
$27.0-31.2$ & $31 / 2$ \\
$31.3-35.8$ & 4 \\
$35.9-40.7$ & $41 / 2$ \\
$40.8-46.2$ & 5 \\
$46.3-52.2$ & $51 / 2$ \\
$52.3-58.7$ & 6 \\
$58.8-65.7$ & $61 / 2$ \\
$65.8-73.2$ & 7 \\
$73.3-81.2$ & $71 / 2$ \\
$81.3-89.7$ & 8 \\
$89.8-98.9$ & $81 / 2$ \\
$99.0-108.9$ & 9 \\
$109.0-119.7$ & $91 / 2$ \\
$119.8-131.2$ & 10 \\
$131.3-143.7$ & $101 / 2$ \\
$143.8-157.2$ & 11 \\
$157.3-171.9$ & $111 / 2$ \\
$172.0-187.9$ & 12 \\
$188.0-204.0$ &
\end{tabular}


Then the mesomorphic component was evaluated using the width of the elbow and knee joints measured with a bow-shaped compass and the values of the arm circumferences and lower legs measured with an anthropometric tape. Measurement of the elbow joint width was made in a sitting position where the participant's arms were positioned along the body, the elbow joint was bent to 90 degrees, the hands were relaxed and open. The measurement was taken in the distal part of the humerus. The distance between the two condyles of the humerus (medial and lateral) was measured. The width of the knee joint was also measured in a sitting position where the joints of the lower limb were in a 90-degree flexion. The distance between the femoral condyles (medial and lateral) at the distal right and left femur was measured. After measuring the joint width, the participant was asked to stand up. The exact height and weight of the player was given to the researcher by the trainer. Then corrected measurements of the arm and lower leg were made. The corrected measurement was preceded by a measure of the circumference at rest at the widest point of the biceps muscle on the right and left side. The corrected arm circumference was performed in a sitting position when the biceps of the arm was in tension. Then the obtained values were substituted to the formula:

$$
\begin{aligned}
& \text { value of arm circumference in tension - skin-fat fold value on arm } \\
& =\text { corrected arm circumference }
\end{aligned}
$$

The next step in the test procedure was to perform a corrected measurement of the lower leg circumference. Lower limbs were placed in a tension-free position (sitting position). The measurements were taken at the widest point of the calf triceps muscle on the right and left side. The measurement was made using an anthropometric tape. Then the skin-fat fold was measured on the right and left shank, vertically in the middle of the length of the calf threeheaded muscle. The obtained values were substituted to the formula:

value of the lower leg circumference - the value of the skin-fat fold on the lower leg $=$ corrected lower leg circumference

The obtained values: body height, elbow width, knee width, corrected circumference of the arm and shank were referred to the nearest values in the table for mesomorph assessment (Table 2).

Table 2. Fragment of a tablet- the second somatotype component - mesomorphy [22]

\begin{tabular}{ccccc} 
Body height & Elbow width & Knee width & $\begin{array}{c}\text { Arm } \\
\text { circumference } \\
\text { after subtraction } \\
\text { of fatty folds }\end{array}$ & $\begin{array}{c}\text { Calf } \\
\text { circumference } \\
\text { after subtraction } \\
\text { of fatty folds }\end{array}$ \\
\hline 193.0 & 7.24 & 10.32 & 33.0 & 38.6 \\
189.2 & 7.09 & 10.12 & 32.3 & 37.9 \\
185.4 & 6.95 & 9.91 & 31.7 & 37.1 \\
181.6 & 6.80 & 9.70 & 31.0 & 36.3 \\
177.8 & 6.65 & 9.40 & 30.3 & 35.5 \\
174.0 & 6.51 & 9.28 & 29.7 & 34.7 \\
170.2 & 6.36 & 9.08 & 29.0 & 34.0 \\
166.4 & 6.22 & 8.87 & 28.3 & 33.2 \\
162.6 & 6.07 & 8.66 & 27.7 & 32.4 \\
158.7 & 5.93 & 8.45 & 27.0 & 31.6 \\
154.9 & 5.78 & 8.24 & 26.3 & 30.9 \\
151.1 & 5.63 & 8.04 & 25.7 & 30.1 \\
147.3 & 5.49 & 7.83 & 25.0 & 29.3 \\
143.5 & 5.34 & 7.62 & 24.4 & 28.5 \\
139.7 & 5.20 & 7.41 & 23.7 & 27.7 \\
135.9 & 5.05 & 7.21 & 23.0 & 27.0 \\
\hline
\end{tabular}


The athletes' body height was the reference point for the other four measurements. The distance of each measurement was calculated from the series in which the value of the body height was the most similar to the location for measuring the previously indicated reference point. All deviations were added, then the obtained value was substituted into the formula:

$$
4+D / 8=\text { mesomorphic value }
$$

where: 4 - accepted average value related to height; D - deviation

The ectomorphic component was last to be evaluated, by the following formula:

$$
\frac{\text { body height }}{\sqrt[3]{\text { bodyweight }}}
$$

Tabulated numerical inverts of the cube body weight were used. Body weight was given by people training during the test. The value read from the table was multiplied by the body height. The obtained numerical value of the slenderness index was read from the table. The resulting three-digit code was applied to the somatogram (a graphic way of determining the type of body physique) (Table 3).

Table 3. The somatotype component - ectomorphy [22]

\begin{tabular}{cc}
$\begin{array}{c}\text { Slenderness indicator, values } \\
\text { body height }\end{array}$ & Value \\
$\begin{array}{c}\text { For } 39.65 \\
\text { body weight }\end{array}$ & \\
\hline $39.66-40.74$ & $1 / 2$ \\
$40.75-41.43$ & 1 \\
$41.44-42.13$ & $11 / 1$ \\
$42.14-42.82$ & 2 \\
$42.83-43.48$ & $21 / 2$ \\
$43.49-44.18$ & 3 \\
$44.19-44.84$ & $31 / 2$ \\
$44.85-45.53$ & 4 \\
$45.54-46.23$ & $41 / 2$ \\
$46.24-46.92$ & 5 \\
$46.93-47.58$ & $51 / 2$ \\
$47.59-48.25$ & 6 \\
$48.26-48.94$ & $61 / 2$ \\
$48.95-49.63$ & 7 \\
$49.64-50.33$ & $71 / 2$ \\
$50.34-50.99$ & 8 \\
$51.00-51.68$ & $81 / 2$ \\
\hline
\end{tabular}




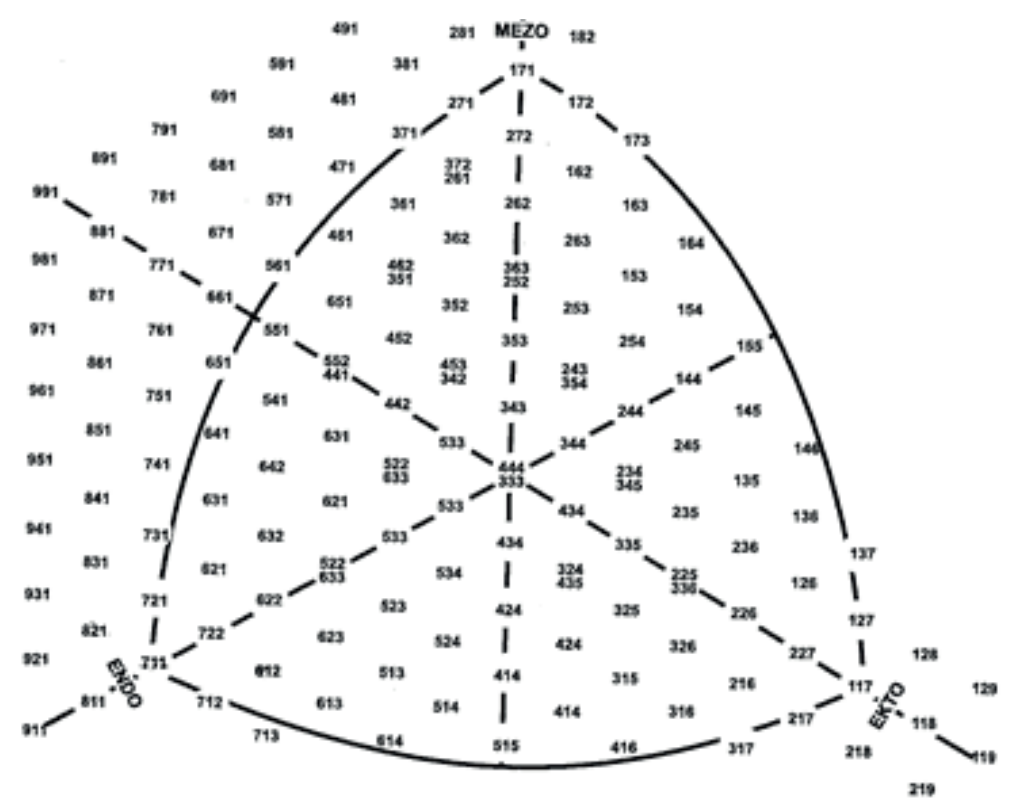

Fig. 1. Somatogram in Sheldon's typology in the Heath-Carter modification [22]

\section{RESULTS}

Analysis of the obtained results showed that a group of men with physical disabilities practicing swimming regularly has the advantage of endomorphic and mesomorphic components. A similar distribution of components in the somatotype was demonstrated by men playing sitting volleyball. A mixed body type was demonstrated among the subjects belonging to the indicated sports groups. The indicated body type is associated with the specificity of physical effort used during training. While swimming and playing sitting volleyball, they focus on shaping endurance, agility and strength. The complexity of training thus affects the body type of men with disabilities practicing the previously indicated sports. The obtained results showed statistically significant similarity between both groups. Men lifting weights clearly showed the dominance of the mesomorphy component and to a small extent the share of the ectomorphy and endomorphy component. It was noticed that the distribution of individual components of the somatotype of men lifting weights is related to the type of effort that accompanies the barbell press or weights lifting. Strength training, static training prevails in the indicated discipline. The competitors present a massive physique because it is related to the type of muscle work they do during strength training. The figure below shows the percentage share of components in individual somatotypes in the group of swimming, sitting volleyball and weight lifting people (Fig. 2).

In order to assess the value of correlation coefficients between individual somatotypes in selected groups of athletes, a nonparametric Spearman's correlation coefficient was used. The obtained results were considered statistically significant when the significance level did not exceed 0.05. Figures 3-6 below show a graphic picture of correlation with 95\% confidence interval marked. After taking into account the measurement error, the correlation indicates a $95 \%$ probability of the accuracy of the obtained results.

The analysis of the following correlation results indicates a high correlation of endomorphy and mesomorphy among the group of swimming men with 
disabilities. The slenderness of the body must be proportional to the measure of massiveness of swimmers to increase the efficiency of work during training in the pool. Weaker correlations between ectomorphic and endomorphic (Fig. 3) as well as ectomorphic and mesomorphic (Fig. 4) components were observed. The weaker correlation between components is related to the body structure of the disabled player and the type of physical activity such as swimming.

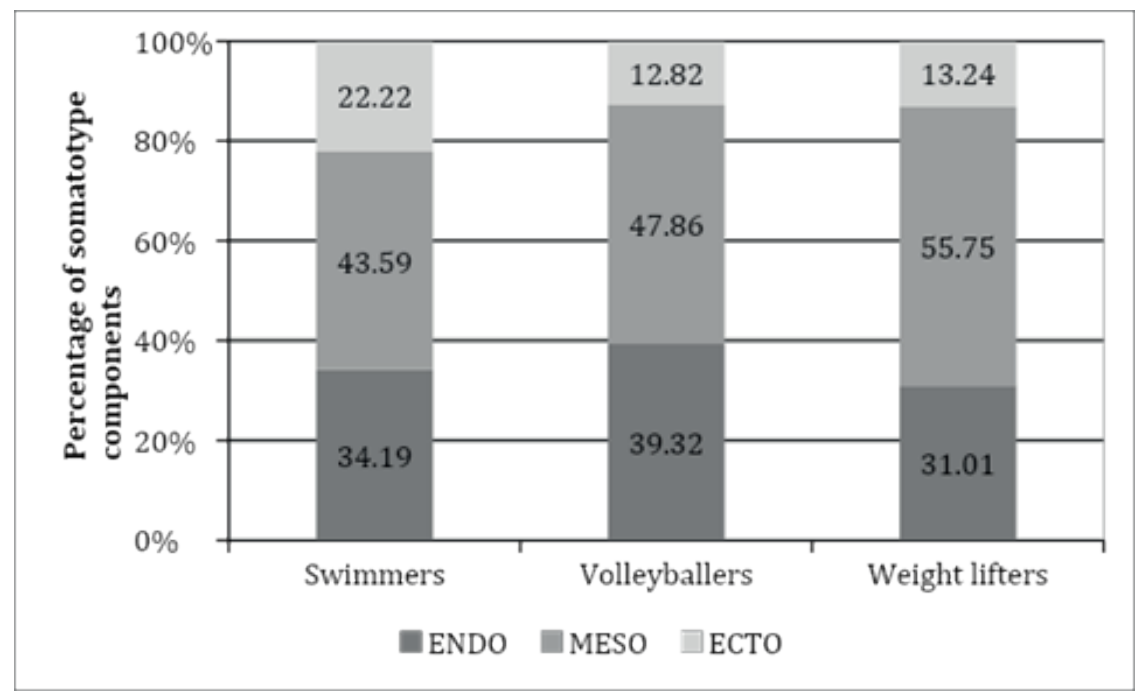

Fig. 2. Percentage of somatotype components found in individual physical activities of athletes with disabilities

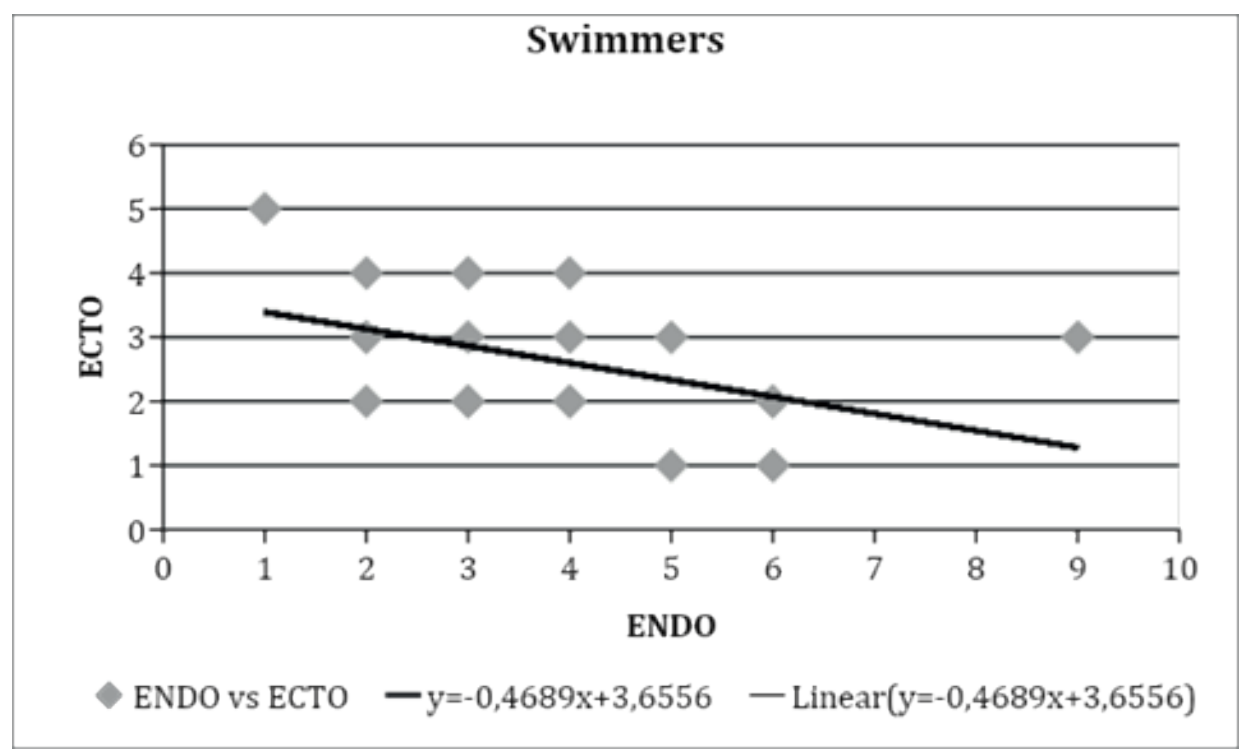

Fig. 3. Correlation of endomorphy and ectomorphy in disabled swimmers 


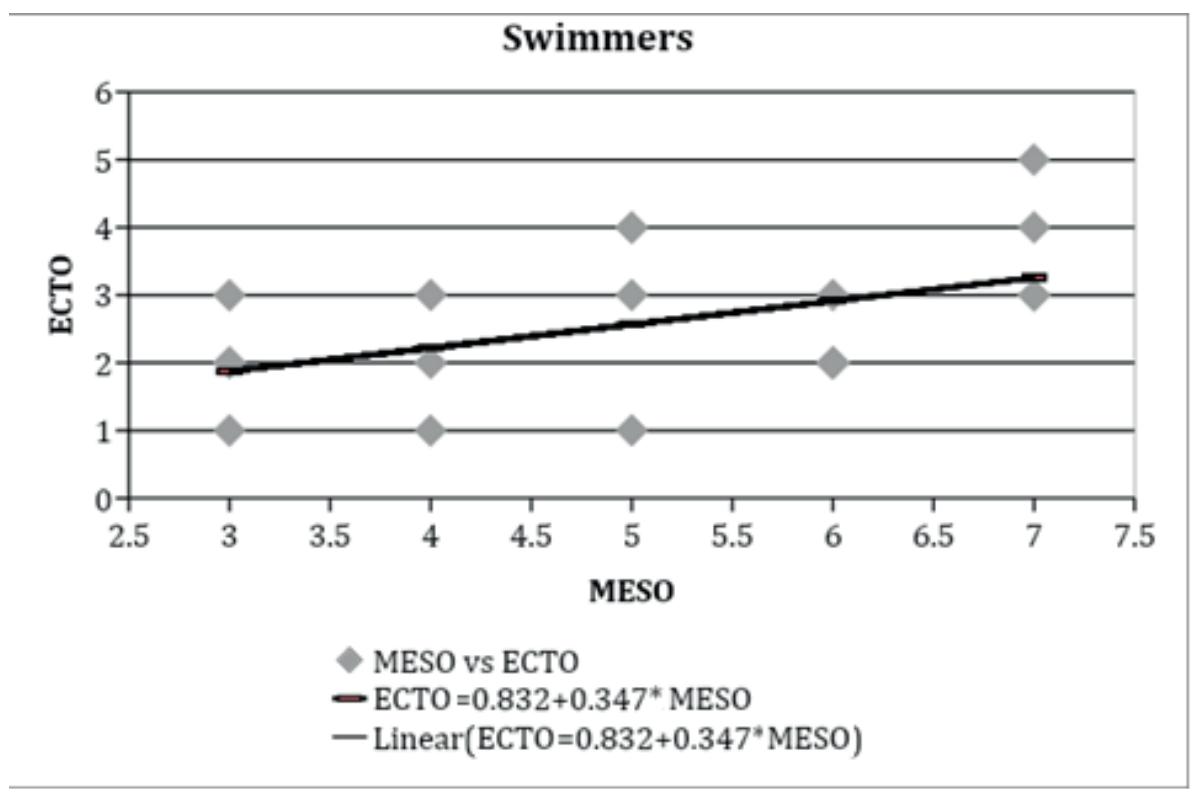

Fig. 4. Correlation of mesomorphy and ectomorphy in disabled swimmers

In the group of volleyballers, a relationship was observed related to the value of ectomorphy and endomorphy. The higher the ectomorphic value was, the lower was the value of the endomorphic component. There is a tight relationship between mesomorphism and ectomorphism where $r=-0.85$, meaning that the increase in mesomorphic features is accompanied by a decrease in ectomorphic features. Men playing sitting volleyball with a higher measure of body fat would show a smaller measure of slenderness, thus affecting the quality of agility and speed of players during the game. The relationship between somatotype components of volleyballers is shown in the figure below (Fig. 5).

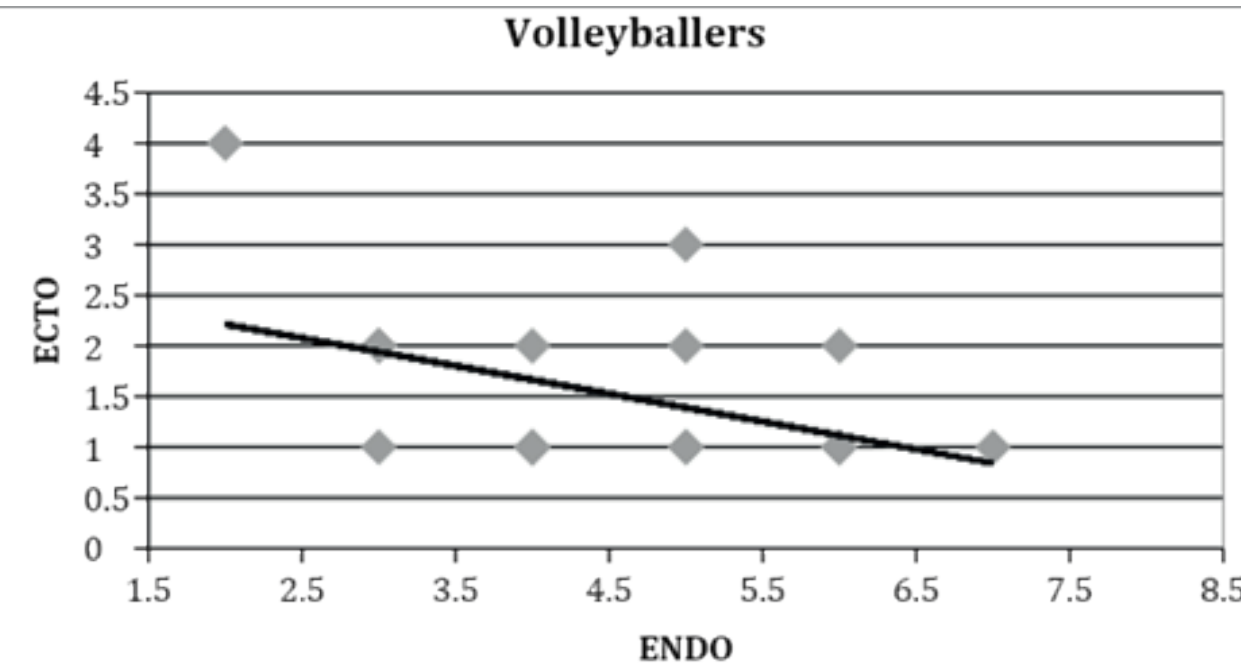

ENDO vs ECTO - Linear(undefined)

Fig. 5. Correlation of endomorphy and ectomorphy in disabled volleyballers 
The results describing the group of men with mobility disabilities lifting weights showed a significant value of mesomorphy $r=-0,8459$ (Fig. 6). The correlation indicates the dominance of the mesomorphic component in men lifting weights, calling their mesomorphic body structure. Athletes with physical disabilities lifting weights have extensive muscle mass and increased body weight, which probably significantly affects their agility. One of the men had a type of ectomorphic structure. The authors say that it could be related to the adaptation of other types of loads during training associated with the type of motor dysfunction of a man lifting weights.

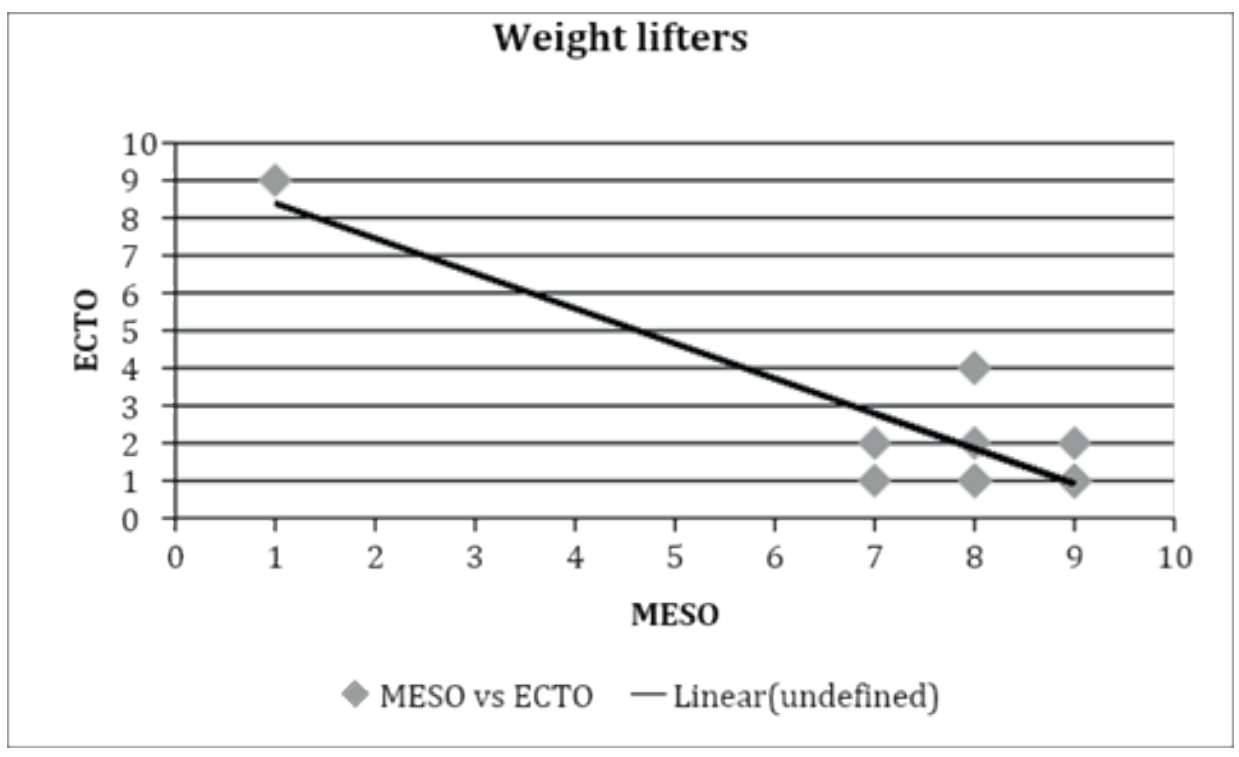

Fig. 6. Correlation of mesomorphy and ectomorphy in disabled weights lifters

Men lifting weights significantly differed in their body type from other athletes. Mesomorphy was a common component of the body structure of all men; however, it significantly dominated among people lifting weights. The table below presents the percentage characteristics of the distribution of endomorphic, mesomorphic and ectomorphic components (Table 4).

Table 4. Percentage characteristics of the endomorphic, mesomorphic and ectomorphic distribution components in individual physical activities

\begin{tabular}{cccc}
\hline Group & Variable & N [\%] & $\begin{array}{c}\text { Standard } \\
\text { deviation }\end{array}$ \\
\hline \multirow{3}{*}{ Swimmers } & ENDO & 34.19 & \\
& MESO & 43.59 & $20(100 \%)$ \\
\hline \multirow{2}{*}{ Volleyballers } & ECTO & 22.22 & \\
& ENDO & 39.32 & $200 \%)$ \\
\hline \multirow{2}{*}{ Weight lifters } & MESO & 47.86 & \\
& ECTO & 12.82 & $20(100 \%)$ \\
\hline
\end{tabular}

Below, the authors present the values of selected descriptive statistics between the somatotype components of athletes with disabilities in various physical activities (Table 5). 
Table 5. Values of selected descriptive statistics (arithmetic mean and standard deviation)

\begin{tabular}{ccccccc} 
Group & Variable & N & $\begin{array}{c}\text { Arithmetic } \\
\text { mean }\end{array}$ & $\begin{array}{c}\text { Standard } \\
\text { deviation }\end{array}$ & Median & Dominant \\
\hline \multirow{3}{*}{ Swimmers } & ENDO & 20 & 4 & 1.95 & 4 & 2 and 4 \\
& MESO & 20 & 5.1 & 1.45 & 5 & 6 \\
\hline \multirow{5}{*}{ Volleyballers } & ECTO & 20 & 2.6 & 1.1 & 2.5 & 2 \\
\hline \multirow{5}{*}{ Weight lifters } & ENDO & 20 & 4.6 & 1.31 & 4.5 & 4 \\
& MESO & 20 & 5.6 & 1.96 & 6 & 6 \\
& ECTO & 20 & 1.5 & 0.83 & 1 & 1 \\
\hline & ENDO & 20 & 4.45 & 1.96 & 4 & 3 \\
& ECTO & 20 & 8 & 1.78 & 8 & 9 \\
\hline
\end{tabular}

\section{DISCUSSION}

It is very difficult to refer to the indicated topics of the somatotype of athletes with physical disabilities depending on the activity of their activity in the literature. Stanković et al. researched somatotypes of able-bodied swimmers (17 years old) and athletes (20 years old) according to Sheldon's typology in Heath-Carter management. In the obtained results, they noticed that a group of athletes was presented with a balanced mesomorphic somatotype, mixed swimmers, ectomorphic-mesomorphic type. Their study groups referred to students whose body type was mesomorphic-endomorphic [23]. The authors of the presented research came to the similar search results, while assessing swimmers with physical disabilities. However, a different distribution of the somatotype was noticed. Disabled swimmers presented a mixed body type where the ectomorphic component was a small percentage. The dominant components were endomorphy and mesomorphy. The authors think that the differences in the obtained results are associated with the presence of disability, which has a big impact on significant characteristics of athletes' bodies. Tolga et al. evaluated non-healthy and young swimmers (12 years old) dividing them by gender. They noticed that the swimming boys also presented a mixed type of somatotype, where the mesomorphic component was dominant, the endomorphic component was slightly less dominant while again the ectomorphic one had the smallest share [24]. Loo et al., using Sheldon's methodology in Heath-Carter modification, received results referring to able-bodied swimming athletes of varying degrees of competition. The men were 21 years old and swam professionally. Their somatotype was also mixed, and the mesomorphic component took over. Again, a small share of the ectomorphic component in the total somatotype was noticed [25]. Seidel et al. also received confirmation that disabled swimmers' dysfunction affects their body type. Just as the authors of this publication, they received the endomorphic-mesomorphic somatotype in disabled swimmers where the ectomorphic component had a small share. Saidel et al. pointed out that the somatotype in the conducted tests may differ due to deformation or deficit of the upper or lower limbs or both [21]. Dahri et al. studied able-bodied men lifting weights referring to the same group interval as the authors of this article. The researchers rightly highlighted the starting categories of the competitors, taking into account the weight range in which they compete. The mesomorphic component was dominant just like in physically disabled men. The endomorphic and ectomorphic component was dependent on the type of weight category [26]. It should be emphasized that able-bodied men lifting weights and physically disabled athletes have different qualification systems during the competition. This aspect affects the types of loads that 
competitors take in a given category and the presence of a movement deficit affects the differences in body somatotype between the indicated groups. Aguero distinguished sports disciplines such as swimming, weight lifting, rugby and table tennis among the surveyed Paralympians. He analyzed the somatotype using the protocol of the International Society Advancement Kinanthropometry (ISAK) and Sheldon's typology in Heath-Caerter modification. He examined the men and women participating at the 2015 Paralympic Games in Toronto. Referring his considerations to the group of men swimming and lifting weights, Aguero received both groups of mesomorphic body structure, where the mesomorphic component dominated. However, referring to the entire study group, men in all sports disciplines showed a mixed type (endomorphicmesomorphic) [27].

Toselli and Campa examined the somatotype of able-bodied volleyballers who play professionally referring to the same age range as the authors of this publication. The competitors presented the ectomorphic-mesomorphic type with a small share of endomorphy. One more time, a mixed body type of athletes who have mixed type activity was seen [5]. The authors of this publication also received a mixed somatotype among men with mobility disabilities playing sitting volleyball. However, volleyballers showed a mesoendomorphic somatotype with a small share of the ectomorphic component. Analyzing the results obtained by Toselli and Camp and the results of own research, it can be concluded that the possibility of active movement of ablebodied volleyballers during the game more effectively shapes the slenderness of physique, i.e. the ectomorphic component. When sitting, players do not generate the same agility and activity as non-disabled volleyballers. Disabled volleyballers moving while sitting on the pitch activate the shoulder girdle and upper limbs more, which increases their strength and muscle mass, thus reducing the ectomorphic component. Campa et al. analyzed somatotypes of non-disabled athletes practicing volleyball, rugby and football. Additionally, they used the BIVA system to supplement the research. Volleyball players are classified as a type of mesomorphic-ectomorphic somatotype [28]. The obtained results were slightly different from those obtained by Toselli and Camp in 2018. The participation between the mesomorphic and ectomorphic component varies; however, the results show that it is very similar, and the component's contribution could be focused on varied volleyball training.

A small number of publications regarding the assessment of the participation of somatotype components in individual physical activities of men with mobility disabilities makes it impossible to explicitly refer to their own research. Most of the available literature describes the body type of able-bodied female and male athletes. According to the authors of this study, it is difficult to compare the somatotype of physically disabled swimmers, weight lifters and volleyballers with non-disabled players. However, there are many similarities with the somatotypes of individual sports groups. It is worth undertaking the extension of the indicated topic in the article because knowing the appropriate body somatotype will affect the quality of training procedures. Analyzing the research methodology, the need to modify the Heath-Carter procedure to meet the needs of anthropometric measurements for athletes with disabilities is noticed. Sheldon's typology in Heath-Carter modification is helpful in preparing anthropometric measurements and in determining the somatotype; however, it does not take into account aspects of various mobility disabilities. 


\section{LIMITATIONS}

Own research had limitations related to the size of the study group. However, the indicated population was sufficient to perform statistical analyses. The researchers are aware that the studies were not fully randomized and they see that it would be worth gathering a control group in the future. Focusing only on the group of men with physical disabilities who perform various types of activity, indicated the trend of shaping the athlete's figure in relation to the practiced sports discipline.

\section{CONCLUSIONS}

A properly calculated somatotype allows disabled athletes to learn about body composition components and to train and develop more effectively in a particular physical activity. Although physically deficient athletes differ from able-bodied men practicing the same activities, their somatotype is similar to people with an efficient movement apparatus. The authors of this publication believe that it is worth exploring knowledge about the physique of disabled athletes, because it will increase their effectiveness during physical activity and will allow them to choose the right training to shape adequate motor skills.

\section{REFERENCES}

[1] Laura Rivas G, Mielgo-Ayuso J, Norte-Navarro A, Cejuela R, Dolores Cabañas M, Martínez-Sanz J. Body composition and somatotype in university triathletes. Nutr Hosp. 2015 Aug 1;32(2):799-807. http://doi.org/10.3305/nh.2015.32.2.9142

[2] Sterkowicz-Przybycień K, Gualdi-Russo E. Evaluation of somatotype in artistic gymnastics competitors: A meta-analytical approach. J Sports Med Phys Fitness. 2019;59(3):449-455. https://doi.org/10.23736/ S0022-4707.18.08332-9

[3] Barbieri D, Zaccagni L, Babić V, Rakovac M, Mišigoj-Duraković M, Gualdi-Russo E. Body composition and size in sprint athletes. J Sports Med Phys Fitness. 2017 ;57(9):1142-1146. http://doi.org/10.23736/ S0022-4707.17.06925-0

[4] Gutnik B, Zuoza A, Zuozienè I, Alekrinskis A, Nash D, Scherbina S. Body physique and dominant somatotype in elite and low-profile athletes with different specializations. Medicina (Kaunas). 2015;51(4):247-52. https://doi.org/10.1016/j.medici.2015.07.003

[5] Toselli, S, Campa F. Anthropometry and functional movement patterns in elite male volleyball players of different competitive levels. J Strength Condition Res. 2018; 32(9):2601-2611. https://doi.org/10.1519/ JSC.0000000000002368

[6] Martín-Matillas M, Valadés D, Hernández-Hernández E, et al. Anthropometric, body composition and somatotype characteristics of elite female volleyball players from the highest Spanish league. J Sports Sci. 2014;32(2):137-48. https://doi.org/10.1080/02640414.2013.809472

[7] Giannopoulos N, Vagenas G, Noutsos K, Barzouka K, Bergeles N. Somatotype, level of competition, and performance in attack in elite male volleyball. J Hum Kinet. 2017 Aug 1;58:131-140. https://doi. org/10.1515/hukin-2017-0082

[8] Blauwet CA. More than just a game: the public health impact of sport and physical activity for people with disabilities (The 2017 DeLisa Lecture). Am J Phys Med Rehabil. 2019;98(1):1-6. https://doi. org/10.1097/PHM.0000000000001063

[9] Comella A, Hassett L, Hunter K, Cole J, Sherrington C. Sporting opportunities for people with physical disabilities: Mixed methods study of web-based searches and sport provider interviews. Health Promot J Austr. 2019;30(2):180-188. https://doi.org/10.1002/hpja.31

[10] Slater G, O'Connor H. Optimising physique for sports performance. Best Practice Protocols for Physique Assessment in Sport.2017: 27-36. https://doi.org/10.1007/978-981-10-5418-1_3

[11] Pastuszak A, Gajewski J, Buśko K. The impact of skinfolds measurement on somatotype determination in Heath-Carter method. PLoS ONE.2019;14(9). https://doi.org/10.1371/journal.pone.0222100

[12] Yang LT, Wang N, Li ZX, Liu C, He X, Zhang JF et al. Study on the adult physique with the HeathCarter anthropometric somatotype in the Han of Xi'an, China. Anat Sci Int. 2016;91(2):180-187. https://doi.org/10.1007/s12565-015-0283-0

[13] Raković A, Savanović V, Stanković D, Pavlović R, Simeonov A, Petković E. Analysis of the elite athletes' somatotypes. Acta Kinesiol. 2015;9(1):47-53.

[14] Orvanová E. Somatotypes of Weight Lifters. J Sports Sci.1990;8(2):119-37. https://doi. org/10.1080/02640419008732139

[15] Lameira-de Oliveira G, Soares de Pinho-Gonçalves P, Perini-de Oliveira AT, Valentim-Silva JR, RoquettiFernandes P, Fernandes-Filho J. Body composition and somatotype of athletes of Brazilian w5-a-side football team: Paralympic team Rio. Rev. fac. med. 2018;66(1). https://doi.org/10.15446/revfacmed. v66n1.61069 
[16] Wojtasik W, Szulc A, Kołodziejczyk M, Szulc A. Wybrane zagadnienia dotyczące wpływu wysiłku fizycznego na organizm człowieka [Selected issues concerning the impact of physical exercise on the human organism]. J Educ Health Sport. 2015;5(9):350-372.

[17] Kopański R, Kopański D, Pryimakov O. Przegląd metod i systemów treningowych w wyciskaniu sztangi leżąc [Review of the methods and burn-in systems in pressing of barbell lying down]. Sport Pedagogy. 2009. Polish. https://www.sportpedagogy.org.ua/html/journal/2009-07/09korbld.pdf

[18] Loturco I, A Pereira L, Winckler C, Santos WL, Kobal R, McGuigan M. Load-velocity relationship in national Paralympic powerlifters: a case study. Int J Sports Physiol Perform. 2019. 1;14(4):531-535. https://doi.org/10.1123/ijspp.2018-0452

[19] Androulakis-Korakakis P, Langdown L, Lewis A, et al.The effects of exercise modality during additional 'high-intensity interval training' upon aerobic fitness and strength in powerlifting and strongman athletes. J Strength Condition Res. 2017;1. https://doi.org/10.1519/JSC.0000000000001809

[20] Puce L, Marinelli L, Pierantozzi E, et al. Training methods and analysis of races of a top level Paralympic swimming athlete. J Exerc Rehabil. 2018.24;14(4):612-620. https://doi.org/10.12965/ jer.1836254.127

[21] Seidel W, Szafraniec R, Pukalski-Pukała P. Analiza wybranych parametrów antropometrycznych pełnosprawnych i niepełnosprawnych pływaków [An analysis of selected anthropometric parameters of able-bodied and disabled swimmers]. Rozprawy Naukowe Awf Wrocław. 2012;39(4):78-83. Polish.

[22] Łaska-Mierzejewska T. Zeszyt do ćwiczeń antropologii [Anthropology worksheets]. Warszawa: Wydawnictwo Naukowe WSKFiT; 2010, 55-65. Polish

[23] Stanković D, Pavlović R, Petković E, Raković A, Puletić M. The somatotypes and body composition of elite track and field athletes and swimmers. Int J Sport Sci. 2018.8(3):67-77. http://doi.org/10.5923/j. sports.20180803.01

[24] Akșđt T, Özkol Z, Vural F, Pekünlü L, Aydinoğlu R, Varol R. Contribution of anthropometric characteristics to critical swimming velocity and estimated propulsive force. J Phys Educ Sport. 2017;17(1) Art 32:212-218. https://doi.org/10.7752/jpes.2017.01032

[25] Loo LH, Wilson NC, Chai WJ. Anthropometric profiles of Malaysian elite swimmers. 3rd International Conference on Movement, Health and Exercise. MoHe. 2016:101-105. https://doi.org/10.1007/978981-10-3737-5_21

[26] Dachri H, Mimouni N. Etude de la somatotypie des haltérophiles africains. University of Biskra; 2018. No 19

[27] Durán-Agüero S, Valdés-Badilla P, Varas-Standen C, Arroyo-Jofre P, Herrera-Valenzuelaf T. Perfil antropométrico de deportistas paralímpicos de élite chilenos. Span J Hum Nutr Diet. 2016;0(4):307-315. https://doi.org/10.14306/renhyd.20.4.253

[28] Campa F, Analiza MS, Talluri J Matias CN, Badicu G, Toselli S. Somatotype and bioimpedance vector analysis: a new target zone for male athletes. Sustainability. 2020;12(11):4365; https://doi. org/10.3390/su12114365 